\title{
NATUREZA, BEM-VIVER E DESENVOLVIMENTO COM EQUIDADE: UMA INTRODUÇÃO AO NOVO CONSTITUCIONALISMO ECONÔMICO LATINO-AMERICANO
}

\author{
NATURE, WELL LIVING AND DEVELOPMENT WITH EQUITY: AN \\ INTRODUCTION TO THE NEW LATIN AMERICAN ECONOMIC \\ CONSTITUTIONALISM
}

\author{
Álisson José Maia Melo*
}

\begin{abstract}
Resumo
Busca-se investigar acerca da existência de um novo modelo de Constituição Econômica no Novo Constitucionalismo Latino-Americano, em especial, nas recentes Constituições do Equador (2008) e da Bolívia (2009). São examinados alguns aspectos econômicos presentes nessas Constituições, em especial: o pluralismo jurídicoeconômico, a democracia econômica, a soberania econômica, a distribuição socioambiental dos resultados econômicos, o desenvolvimento do mercado interno, a natureza como recurso econômico e a vedação ao monopólio e oligopólio. Num exame crítico, arremata-se que, embora essas cartas constitucionais examinadas permaneçam afirmando um modelo desenvolvimentista, de fato, elas apontam para uma nova proposta de desenvolvimento, baseada no pluralismo econômico, mediante a imposição maiores restrições de cunho socioambiental para a livre iniciativa.
\end{abstract}

Palavras-chave: Novo Constitucionalismo Latino-Americano. Constituição econômica. Bem-viver. Desenvolvimento. Pluralismo jurídico.

\begin{abstract}
It intends to investigate on the existence of a new model of Economic Constitution within the New Latin American Constitutionalism, especially in the recent Constitutions of Ecuador (2008) and Bolivia (2009). Some economic aspects in these constitutions are examined, particularly: the legal-economic pluralism, economic democracy, economic sovereignty, environmental distribution of economic results, the development of the internal market, the nature as an economic resource and prohibition of monopoly and oligopoly. In a critical analysis, it concludes that, although these constitutions remain stating a developmental model, in fact, they point to a new development proposal based on economic pluralism by imposing greater socio-environmental restrictions for free enterprise.
\end{abstract}

Keywords: New Latin American Constitutionalism. Economic constitution. Well living. Development. Legal pluralism.

\footnotetext{
* Doutorando pelo Programa de Pós-Graduação em Direito da Universidade Federal do Ceará (PPGD/ UFC). Mestre em Direito pela UFC. Professor universitário. E-mail: alisson.melo@gmail.com
} 
Natureza, Bem-Viver e Desenvolvimento com Equidade [...]

\section{INTRODUÇÃO}

Cientistas do Direito vêm analisando os fenômenos constitucionalistas ocorridos nas últimas décadas como integrantes de um processo progressivo de emancipação e autenticidade jurídico-política. Para uns, a primeira fase seria iniciada com a Constituição brasileira de 1988 e incluiria a colombiana de 1991, com caráter social e descentralizador; a segunda fase, desenvolvida pela Constituição venezuelana de 1999, traria a participação popular e o pluralismo; e a terceira fase, representada pelas Constituições equatoriana de 2008 e boliviana de 2009, consagraria o plurinacionalismo comunitário, a interculturalidade e o pluralismo igualitário jurisdicional (WOLKMER, 2011, p. 153; WOLKMER; FAGUNDES, 2011, p. 403) . Para outros, consideram-se os processos constituintes desenvolvidos em suas décadas: assim, a primeira fase, desenvolvida nos anos 1980, teria como Cartas Políticas a argentina e a brasileira; a segunda, nos anos 1990, incluiria as Constituições colombiana e venezuelana; e a terceira representada pelas Constituições equatoriana e boliviana, ocorridas nos anos 2000 (TÁRREGA; GONÇALVES, 2016, p. 75-76). Sem prejuízo do reconhecimento da existência de três fases do constitucionalismo na América Latina, adota-se uma distinção forte para reconhecer na última fase características significativas que justifiquem atribuir a essa exclusivamente um tom de novidade.

O Novo Constitucionalismo Latino-Americano, para os fins do presente estudo, caracteriza-se pelos seguintes aspectos: trata-se de um produto das reivindicações sociais, provocando um pluralismo jurídico sem uma necessária coesão teórica; há subjacente à discussão constitucional preocupações relativas à legitimidade democrática da Constituição, num constitucionalismo democrático de caráter radical e revolucionário, renovando a relação entre Constituição e titular do poder constituinte, para emancipação dos povos (VICIANO PASTOR; MARTÍNEZ DALMAU, 2011, p. 7); e introduz nos textos constitucionais a autonomia política dos povos originários (VICIANO PASTOR; MARTÍNEZ DALMAU, 2011, p. 22) e os direitos da natureza, atribuindo a esta a condição de pessoa, com fundamento menos científico que cultural de origem ancestral (ZAFFARONI, 2010, p. 120-121). Essa fase do constitucionalismo latino-americano está concretizada particularmente em duas iniciativas: no Equador, em 2008, e com a Bolívia, em 2009. Como estratégia heurística da pesquisa, traz-se, sempre que possível, a leitura econômica da Constituição brasileira de 1988, servindo-se de 
controle, para contrastar a distinção qualitativa substancial entre os modelos constitucionais.

O problema a que se propõe a presente pesquisa é identificar se as Constituições do Equador (2008) e da Bolívia (2009), ao defenderem o Bem-viver, estabelecem um novo modelo econômico para o mundo. Entre os objetivos, busca-se, inicialmente, identificar a existência de constituição econômica dentro das Constituições do Equador e da Bolívia, para, num segundo momento, apontar os caracteres comuns entre elas que possam sugerir a existência de uma tendência entre elas, no sentido de indicar um movimento coerente no constitucionalismo; a partir do exame dessas características comuns, vislumbra-se se a política econômica proposta encontra-se inserida dentro do modelo desenvolvimentista, ou se realmente propõe uma ruptura paradigmática.

Utiliza-se no presente estudo a expressão Bem-viver (BRANDÃO, 2015), para designar o que se denomina nas Constituições do Equador e da Bolívia como buen vivir, vivir bien, sumak kawsay ou suma qamaña, entre outras denominações, ancoradas nos discursos dos povos indígenas desses países (GUDYNAS; ACOSTA, 2011, p. 76). O Bem-viver é um modo de vida oriundo dos saberes tradicionais dos povos originais da América Latina, e cujo conteúdo alcança um bem-estar integral dos povos em harmonia com a natureza numa perspectiva comunitária (BRANDÃO, 2015, p. 149), apartando-se da relação radical trazida pela Modernidade entre sujeito humano (individualimo) e natureza objeto (antropocentrismo). Aliás, a alusão aos direitos da natureza deriva diretamente da adoção da concepção do Bem-viver nessas constituições (MORAES, 2012, p. 15). Além disso, não se pretende incluir na discussão aspectos correlacionados ao tema, como o modelo de gestão fiscal, o de gestão orçamentária e a estruturação do sistema financeiro e monetário nesses países.

O trabalho está dividido em quatro partes. Além desta introdução, apresentam-se breves conceitos e vocações para o Direito Econômico e para as regras de Direito Ambiental no contexto daquele, que vão nortear a análise da pesquisa. Nessa etapa, adota-se claramente o referencial teórico da escola paulista de Direito Econômico. Em seguida, passa-se ao exame das características comuns entre as Constituições do Equador e da Bolívia, no que tange à estruturação de uma Constituição econômica. Ao final, apresentada a crise de identidade, desenvolve-se uma discussão crítica na busca de uma solução. 
Natureza, Bem-Viver e Desenvolvimento com Equidade [...]

\section{A CONSTITUIÇÃO ECONÔMICA E COMO O DIREITO AMBIENTAL DEVE SER COMPREENDIDO À LUZ DO DIREITO ECONÔMICO}

Como parâmetro científico para a definição da perspectiva a ser empreendida neste estudo, cuida-se de examinar certos referenciais teóricos relativos à relação entre Constituição, Direito Econômico e Direito Ambiental. De início, é imprescindível trazer considerações sobre constituição econômica. A noção de constituição econômica surge historicamente com as (mais conhecidas) constituições sociais, logo após o final da Primeira Guerra Mundial - a mexicana, de 1917, e a alemã, de 1919. Tendo como temas centrais nas primeiras constituições sociais o trabalho (a promoção dos direitos dos trabalhadores), a assistência social e a função social da propriedade, é também o mote para a remodelação das relações econômicas em nível constitucional. Em outras palavras, as constituições ditas sociais também empreenderam o reequilíbrio do pacto econômico existente entre as elites e a classe trabalhadora (BERCOVICI, 2005, p. 13-18).

Numa segunda fase, tais constituições aumentaram os aspectos de controle, inicialmente com a função social das empresas, a defesa da concorrência e a repressão ao abuso do poder econômico, e depois ampliando para o debate desenvolvimentista. Já numa terceira fase, especialmente reforçada em 1972, quando aprovada a Declaração de Estocolmo, a questão ambiental passa a ser introduzida nos textos constitucionais. Em síntese, as constituições do século XX estabelecem um modelo de constituição econômica programática e diretiva (BERCOVICI, 2005, p. 33-34).

Vale dizer, as constituições econômicas têm por objetivo estabelecer mudanças nas estruturas econômicas existentes, com vistas a um certo modelo de desenvolvimento elegido pelo texto constitucional. No bojo das constituições econômicas, lidam-se com regras típicas de Direito Econômico, alçadas ao status constitucional, mas que permanecem com suas características singulares típicas, como a plasticidade, entendida como a capacidade de adaptação diante de mudanças nas circunstâncias de conjuntura econômica. Vocacionado para a manutenção do sistema produtivo, o Direito Econômico é o direito do desenvolvimento econômico (DERANI, 2008, p. 47).

O Direito Econômico, enquanto subsistema do Direito, implica inclusive uma nova interpretação de normas oriundas de ramos já consagrados, como o Direito Civil, o Direito do Consumidor e o Direito Administrativo. Dentro dessa discussão, 
cumpre verificar como as normas de Direito Ambiental se comportam inseridas no subsistema de Direito Econômico. A introdução de regras constitucionais de conteúdo ambiental também provoca uma mudança na compreensão do projeto de desenvolvimento proposto para modificação da ordem econômica em vigor. Para Derani (2008, p. 56), o Direito Ambiental "é em si reformador, modificador, pois atinge toda a organização da sociedade atual, [...] que surge para rever e redimensionar conceitos que dispõe sobre a convivência das atividades sociais" (DERANI, 2008, p. 56).

Entretanto, é um engano pensar que as normas de Direito Ambiental, por si sós, remetam à um discurso radicalmente subversivo. Dentro do esquema do Direito Econômico e das constituições econômicas, o Direito Ambiental segue como um discurso de reforço ao modelo de desenvolvimento já adotado culturalmente, ao menos no que concerne ao seu núcleo estrutural. Nas precisas palavras de Derani (2008, p. 55),

\begin{abstract}
Retomando o acima exposto, o conceito de meio ambiente, e conseqüentemente a proteção do meio ambiente, só podem ser pensados e articulados dentro da base social onde se desenvolve a relação homemnatureza. É no interior do desenvolvimento industrial-tecnológico moderno que devem ser encontrados os meios de proteção e conservação dos recursos naturais. Pensar em proteção do meio ambiente é uma clara opção pela continuidade desta sociedade. A natureza continua recurso natural, permanece objeto estranho ao sujeito, por ele somente identificada mediante sua apropriação e transformação (a natureza como recurso é evidenciada na medida de sua utilidade).
\end{abstract}

A vocação econômica do Direito Ambiental, inclusive no âmbito constitucional, sem ignorar sua normatividade específica para proteção dos ecossistemas naturais, é de reforçar, dentro da plasticidade do próprio Direito Econômico, a continuidade do modelo de sociedade industrial-tecnológico, tratando a natureza ainda como recurso econômico à disposição do ser humano e precificado segundo o grau de escassez e as leis da oferta e da demanda. Dito isso, deve-se ter em conta essa observação no tangente às constituições do chamado Novo Constitucionalismo LatinoAmericano, cujo exame a seguir permite verificar o acerto ou desacerto de tal hipótese.

\title{
3 UMA MIRADA NAS CONSTITUIÇÕES ECONÔMICAS DO NOVO CONSTITUCIONALISMO LATINO-AMERICANO
}

Um exame atento aos textos constitucionais das recentes Cartas da Bolívia e do Equador permite identificar neles traços característicos de um modelo de Constituição econômica próprio desse novo movimento. A metodologia aqui caminha em sentido de um positivismo jurídico, buscando levar o texto constitucional a sério, sem prejuízo da necessidade de uma leitura sistêmica. Nesta seção, pretende-se discutir 
Natureza, Bem-Viver e Desenvolvimento com Equidade [...]

esses traços característicos e até que ponto eles podem levar a uma compreensão diferenciada.

Cabe o alerta de que a proposta de sintetizar as características da constituição econômica do Novo Constitucionalismo Latino-Americano aqui intentada não deve ser entendida como compreensiva, ou seja, ela, por ser simplificadora, não trata de modo integral o sistema econômico nas constituições do Novo Constitucionalismo Latino-Americano, mas, em recortes limitantes, indica pontos estruturais, no intuito de didaticamente facilitar a compreensão.

\subsection{Pluralismo jurídico-econômico}

Possivelmente a principal característica das constituições econômicas dos dois países, razão pela qual se trata em primeiro lugar, as Constituições da Bolívia e do Equador promovem uma ampla diversidade de formas de organização da economia. Como apontam Viciano Pastor e Martínez Dalmau (2011, p. 23), os modelos econômicos vão desde a iniciativa privada até a economia comunitária, perpassando pela presença do Estado em questões sensíveis, como a gestão de recursos naturais e a regulação econômica.

Nesse sentido, a Constituição equatoriana cuida de construir o chamado regime de desenvolvimento (Título VI), compreendido como o conjunto organizado, sustentado e dinâmico dos sistemas econômicos, políticos, socioculturais e ambientais, que garantem a realização do Bem-viver ${ }^{1}$. Esse regime de desenvolvimento vai ser concretizado em Planos Nacionais de Desenvolvimento ${ }^{2}$, mais recentemente intitulado de Plano Nacional do Bem Viver. Mais adiante, a Constituição equatoriana vai reconhecer diversas formas de organização da produção na economia, entre elas: comunitárias; cooperativas; empresariais públicas; empresariais privadas; associativas; familiares; domésticas; autônomas; e mistas. ${ }^{3}$

Já no sistema constitucional boliviano, a constituição cuida de denominá-lo de modelo econômico plural, orientado para melhoria da qualidade de vida e o Bemviver dos povos bolivianos, e que busca articular as diferentes formas de organização econômica com base nos princípios de complementariedade, reciprocidade, solidariedade, redistribuição, igualdade, sustentabilidade, equilíbrio, justiça e transparência. Da mesma forma, reconhece uma pluralidade de formas de organização 
econômica, sem prejuízo dos modelos mistos, a saber: comunitária, estatal, privada e social cooperativa. ${ }^{4}$

A indicação desses quatro modelos, em especial, deve implicar uma mudança de compreensão normativa. Logo, o que se deve entender por formas de organização econômica nesse contexto? Talvez a questão não se limite às formas de estabelecimento de iniciativas empresariais, mas vá além para instaurar subsistemas econômicos distintos, não excludentes mas parcialmente fechados — porque há que se reconhecer que, inseridos no mesmo sistema econômico, permanece potencialmente a possibilidade e necessidade de trocas - de organização dos fatores de produção, de relação com a produção econômica e a exploração da natureza e de ponto de equilíbrio na distribuição dos resultados econômicos desse modo de organização. Nesse sentido, confira-se a lição de Raúl Prada Alcoreza (2010, p. 187), para quem a Constituição boliviana propõe uma economia plural, caracterizado por espaços econômicos diferenciados pelas ações, práticas e estruturas, porém entrelaçados e integrados numa relação de articulação e complementação.

Veja-se que tais variáveis vão discrepar drasticamente entre o modo comunitário e o modo privado de organização da produção da economia. A título exemplificativo, a Constituição boliviana traça linhas gerais que diferenciam cada um desses modelos. O modelo de organização econômica privada será respeitado quando cumprir sua função social, e está fundada no direito de propriedade, na liberdade de iniciativa empresarial e no pleno exercício das atividades empresariais, ressaltando a importância dada à industrialização para a superação da condição de dependência às exportações e alcançar uma economia de base produtiva. ${ }^{5} \mathrm{O}$ modelo de organização econômica estatal, por sua vez, volta-se para a proteção dos recursos naturais estratégicos e dos serviços públicos ${ }^{6}$. Já o modelo de organização econômica comunitária compreende os sistemas de produção e reprodução da vida social, fundados nos princípios e na visão próprios dos povos e nações indígenas e campesinas, tendo como meta complementar o interesse individual com o Bem-viver coletivo, apresentada como alternativa solidaria, em que há uma relação de harmonia com o meio ambiente ${ }^{7}$. Por fim, a forma social cooperativa se establece como mecanismo de economia solidária e sem fins lucrativos ${ }^{8}$. Para Raúl Prada Alcoreza (2010, p. 188):

De los cuatro ejes de la economía plural, el comunitario goza de especial atención debido a su larga historia y al papel que le toca jugar en el condicionamiento y dirección de los comportamientos y conductas de la mayoría de la población. La comunidad sigue siendo el referente más fuerte de los trueques, las ferias, el trabajo colectivo, el ayni, la minka, la 
Natureza, Bem-Viver e Desenvolvimento com Equidade [...]

complementariedad subyacente entre los distintos pisos ecológicos, la reciprocidad entre las comunidades.

Na ótica de Brandão (2015, p. 162), ao recolocar o homem como inserido na natureza, o Bem-viver rechaça os modelos colonial de exploração e neoliberal de desenvolvimento. Diante de modelos produtivos substancialmente diferentes e, portanto, conflitantes, vale a colocação feita por Brandão (2015, p. 159), de que haveria "uma centralidade no modelo econômico indígena como princípio organizador do conjunto da sociedade". Sobre a regra de solução no âmbito do Direito Econômico, remete-se esta discussão para o momento derradeiro deste estudo (Seção 3).

\subsection{Democracia econômica}

As constituições do Novo Constitucionalismo Latino-Americano fazem alusão imediata ao princípio da democracia econômica. A Constituição brasileira de 1988 não cuida expressamente do tema, mas há quem defenda a existência desse valor como princípio implícito do sistema. Para Figueiredo (2014, seção 2.5.5), a democracia econômica propõe, de um lado, que as políticas públicas devem almejar o incremento da oferta igualitária das oportunidades tanto de emprego quanto de iniciativa e, por outro lado, a participação de todos os setores econômicos e grupos sociais na elaboração das políticas públicas de planejamento econômico, de modo a harmonizar os interesses envolvidos.

No âmbito das constituições do Novo Constitucionalismo, encontram-se referências expressas voltadas para os objetivos da organização econômica estatal na Constituição da Bolívia ${ }^{9}$. Já na Constituição do Equador temos a alusão em termos mais específicos, relacionados às diversas formas de acesso, a saber:

a) o acesso equitativo aos fatores de produção, em especial aos recursos naturais, a ser promovido pelo Estado; e

b) o acesso aos benefícios provenientes do aproveitamento dos recursos naturais ${ }^{10}$.

Essas mesmas conotações também se encontram na Constituição boliviana $^{11}$. Do ponto de vista contextual do Novo Constitucionalismo LatinoAmericano, contemplando o que foi discutido sobre o pluralismo jurídico-econômico (seção 2.1), pode-se agregar um terceiro aspecto, relacionado com o radical giro democrático feito pelas constituições em exame, que, considerando a existência de modelos diferenciados de organização da economia, vai conferir aos diversos centros de poder democrático, em especial os centros locais, a prerrogativa de deliberar quanto à 
escolha do modelo econômico a ser adotado naquela região, e de que forma se dará a integração entre o modelo eleito com os demais.

\subsection{Soberania econômica}

Enquanto na Constituição brasileira de 1988 há uma singela menção à soberania nacional como princípio da ordem econômica, no art. 170, inciso I (BRASIL, 1988), cuja interpretação conduz à consideração de que "somente existirá Estado soberano onde houver independência econômica. Assim, as normas de direito econômico devem, antes de tudo, primar pela plena garantia de desenvolvimento socioeconômico da Nação" (FIGUEIREDO, 2014, item 2.4.1), as constituições do Novo Constitucionalismo remetem a modalidades específicas de soberania. Sem prejuízo da soberania sobre os recursos naturais, mencionam as soberanias alimentar e energética.

$\mathrm{Na}$ Constituição do Equador, além de ser objeto da política econômica nacional assegurar a soberania alimentar e energética, encontra-se entre os papéis do Estado na promoção do acesso equitativo aos fatores de produção o desenvolvimento de políticas de fomento à produção nacional em todos os setores, especialmente para garantia a soberania alimentar e a energética ${ }^{12}$. Essa Constituição, aliás, traz uma preocupação mais incisiva sobre a soberania alimentar, ao estipular que ela será prioritária em relação à soberania energética, e considerando-a um objetivo estratégico e uma obrigação do Estado para garantir que os povos equatorianos alcancem a autossuficiência de alimentos sadios e culturalmente apropriados de forma permanente $^{13}$.

A Constituição boliviana, por sua vez, põe de relevo a organização da política de produção nacional voltada para a produção de bens e serviços suficientes para cobrir de modo adequado as necessidades básicas do mercado interno ${ }^{14}$. Mais especificamente, ela coloca como objetivo do modelo de organização econômica estatal alcançar a soberania alimentar da população, assim como põe ênfase nas ações do chamado desenvolvimento rural integral sustentável ${ }^{15}$. Não deixa de tratar, oportunamente, da soberania energética, cabendo ao Estado garanti-la através da política nacional de hidrocarbonetos submetida a um desenvolvimento integral, sustentável e equitativo ${ }^{16}$. Ademais, o texto constitucional também cuida de estabelecer um consumo sustentável, relacionando o consumo interno com a produção interna ${ }^{17}$. 
Natureza, Bem-Viver e Desenvolvimento com Equidade [...]

Também sobre a questão da soberania alimentar, levantam-se algumas questões pertinentes mais adiante (seção 3).

\subsection{Distribuição socioambiental dos resultados econômicos}

Avançando no exame das características das constituições econômicas do Novo Constitucionalismo Latino-Americano, é possível observar consideráveis inovações em relação à responsabilidade do sistema econômico de distribuição dos seus resultados para toda a sociedade e para a preservação e conservação ambientais. Em comparação, mais uma vez, com o modelo constitucional brasileiro de 1988, que se limitou praticamente a estabelecer uma tensão entre o fundamento da livre iniciativa e os princípios da propriedade privada e da livre concorrência, de um lado, e o fundamento da valorização do trabalho e os princípios da função social da propriedade, da defesa do meio ambiente, da redução das desigualdades sociais e da busca do pleno emprego, de outro, as constituições do Equador e da Bolívia estabelecem regramentos mais específicos de como essa tensão deve proceder.

A Constituição do Equador, ao tratar do regime de desenvolvimento, estabelece cláusulas gerais de distribuição dos resultados econômicos ao prever como objetivos desse regime a construção de um sistema econômico justo, solidário e sustentável, baseado na geração de trabalho digno e estável, na distribuição igualitária dos meios de produção, dos benefícios do desenvolvimento, e a recuperação e conservação da natureza e a manutenção de um meio ambiente sadio e sustentável que

permita o acesso equitativo, permanente e de qualidade aos recursos ambientais ${ }^{18}$. Além disso, especificamente no tratamento do uso da terra, exige que ela deva cumprir as funções social e ambiental ${ }^{19}$. No âmbito da política econômica de comércio exterior, também estipula que o Estado promoverá as exportações ambientalmente responsáveis e dará preferência àquelas que gerem maior emprego ou valor agregado, em especial as oriundas de pequenos e médios produtores ${ }^{20}$.

A sustentabilidade, enquanto garantia constitucional, exige condutas que realizem as melhores escolhas econômicas que promovam o melhor benefício líquido, incluídos aqui os benefícios sociais e ambientais, de modo que tal escolha possa ser inserida dentro de uma reflexão de longo prazo (FREITAS, 2012). Não se cuida tãosomente de um princípio ambiental, mas de um metaprincípio, para a ação humana intersubjetiva. 
Especificamente em relação à distribuição social, essa constituição traça como responsabilidade do Estado equatoriano, para a promoção da soberania alimentar, a geração de sistemas justos e solidários de distribuição e comercialização de alimentos $^{21}$. Ademais, entre os objetivos da política econômica, incluem-se assegurar uma adequada distribuição da renda e da riqueza nacional e manter a estabilidade econômica, assim entendida como uma relação entre o nível máximo de produção e o nível máximo de emprego sustentáveis no tempo ${ }^{22}$. No âmbito da promoção do acesso equitativo aos fatores de produção, a constituição confere ao Estado equatoriano as missões de evitar a concentração e a acumulação dos fatores de produção e dos recursos econômicos, com remoção de privilégios e desigualdades de acesso e promoção da redistribuição, especialmente para as mulheres, de estimular a difusão dos conhecimentos e tecnologias voltados para o processo de produção, e de promover a democratização do crédito $^{23}$.

Já no que tange aos aspectos ambientais, a Constituição do Equador traça em diversas passagens a relação de sustentabilidade entre a economia e o meio ambiente. Assim, ao reconhecer o direito da população a viver em um meio ambiente sadio e ecologicamente equilibrado, o faz mediante a garantia da sustentabilidade e do Bem-viver, incluindo, entre outras ferramentas jurídicas, a conservação dos ecossistemas e a recuperação dos espaços naturais degradados ${ }^{24}$. A conservação dos ecossistemas, diferenciando-se da preservação ambiental, é o instrumento adequado para concretizar esses processos econômicos sustentáveis travados com o meio ambiente. Nesse sentido, outro objetivo da política econômica equatoriana é promover a incorporação do valor agregado com máxima eficiência, respeitando-se os limites biofísicos da natureza, ou seja, a capacidade de recuperação dos ciclos biológicos ${ }^{25}$. Na linha de raciocínio da conservação ambiental sustentável, a Constituição equatoriana põe como missão do Estado a promoção, tanto no setor público quanto no privado, do uso de tecnologias ambientalmente limpas e de energias alternativas não contaminantes ou de baixo impacto ambiental ${ }^{26}$.

Aos povos indígenas, em suas várias formas de organização, dentro do seu próprio modelo econômico (cf. seção 2.1), essa Constituição vai garantir especialmente, entre os direitos coletivos, o de conservar e promover práticas de manejo da biodiversidade e do seu entorno natural, com vistas à conservação e utilização sustentável dessa biodiversidade, a ser promovida também pelo poder público ${ }^{27}$. 
Natureza, Bem-Viver e Desenvolvimento com Equidade [...]

Num segundo momento, a Constituição equatoriana estabelece um bloco de disposições constitucionais acerca da gestão estatal dos denominados setores estratégicos. São considerados estratégicos, entre outros, os setores energético e hídrico, de recursos não renováveis e da biodiversidade. Com efeito, no âmbito dessa gestão estatal, deverão ser observados os princípios da sustentabilidade ambiental, da precaução, da prevenção e da eficiência ${ }^{28}$. O Estado poderá constituir empresas públicas para gestão desses setores estratégicos, bem como para o aproveitamento sustentável dos recursos naturais ${ }^{29}$. Especificamente em relação aos recursos naturais não renováveis, é estabelecido que eles pertencem ao patrimônio inalienável e imprescritível do Estado e que sua gestão será pautada na responsabilidade intergeracional, na conservação da natureza e na cobrança de contribuições não tributárias e de participações empresariais, com vistas a minimizar os riscos e impactos socioambientais $^{30}$.

No sistema constitucional boliviano, por sua vez, a distribuição social se dá, numa ponta, pela geração de trabalho digno e pela redução das desigualdades de acesso aos recursos produtivos e, noutra ponta, pela erradicação da pobreza, através da geração de produto social e da redistribuição justa dos excedentes econômicos ${ }^{31}$. Já a distribuição ambiental vem através da proteção do meio ambiente pelas formas de organização econômica, mediante a conservação, proteção e aproveitamento sustentável dos recursos naturais e da biodiversidade e a garantia do equilíbrio da natureza ${ }^{32}$.

O Estado possui um papel fundamental nesse processo, no sentido de promover a integração das diferentes formas de produção econômica, a industrialização dos recursos naturais no marco do respeito e proteção do meio ambiente, com o intuito de gerar empregos e insumos econômicos e sociais para a população, e políticas de distribuição equitativa da riqueza e dos recursos econômicos do país ${ }^{33}$. Na gestão ambiental, o aproveitamento sustentável do patrimônio natural será pautada para o benefício da população, garantindo-se acesso equitativo pelo povo boliviano aos benefícios provenientes desse aproveitamento ${ }^{34}$.

Por fim, ao tratar do uso da terra, a Constituição boliviana elucida que a fonte fundamental para a aquisição de propriedade agrária é o trabalho, e prevê as funções social, traduzida no aproveitamento da terra pelos povos e comunidades indígenas e o minifúndio para fins de subsistência, e econômica social, entendida como o emprego sustentável da terra no desenvolvimento de atividades produtivas em benefício da sociedade ${ }^{35}$. 


\subsection{Desenvolvimento do mercado interno}

Outra característica de ambas as constituições é reforçar a proteção do mercado interno, o que ocorre mediante três estratégias normativas: a primeira se dá mediante a promoção e desenvolvimento do mercado interno, especialmente sob o âmbito da industrialização; a segunda se verifica com a promoção dos modelos empresariais de micro e pequena empresas e do modelo associativista; a terceira é a sinalização em favor da priorização das exportações de mercadorias industrializadas contra a exportação de matéria-prima.

Na Constituição da Bolívia, inicia-se com a indicação, entre os princípios a serem observados nas negociações internacionais, da proteção e preferência para a produção nacional e o fomento às exportações ${ }^{36}$. No bojo da economia plural, insere-se como um de seus aspectos a industrialização como forma de superar a dependência da exportação de matérias primas, bem como alcançar um estágio produtivo para a economia de base, apoiada no desenvolvimento sustentável e na harmonia com a natureza ${ }^{37}$. Ademais, a industrialização dos recursos naturais é reconhecida constitucionalmente como meio para atingir o Bem-Viver ${ }^{38}$.

A função do Estado boliviano na economia consiste, entre outros aspectos, promover prioritariamente a industrialização dos recursos naturais, renováveis ou não ${ }^{39}$. Mais especificamente no tocante às políticas econômicas da Bolívia, há uma indicação explícita de que as políticas públicas de indústria e comércio devem garantir uma oferta de bens e serviços suficiente para cobrir as necessidades básicas do país, bem como para fortalecer as exportações ${ }^{40}$. Após manifestar o apoio à organização dos pequenos produtores sob o formato associativo e anunciar a promoção da exportação de bens com valor agregado $^{41}$, a Constituição boliviana estabelece a prioridade da industrialização na política econômica ${ }^{42}$.

\subsection{Natureza como recurso econômico}

Embora a Constituição do Equador tenha sido aclamada pela enunciação dos direitos da natureza, em especial ao respeito integral à existência, manutenção e regeneração dos seus ciclos vitais, estrutura funções e processos produtivos ${ }^{43}$, enquanto a Constituição boliviana tenha sido mais comedida nesse tema, estabelecendo um dever fundamental de proteger e defender um meio ambiente adequado para o desenvolvimento de todos os seres vivos ${ }^{44}$, ambas tratam a natureza, nas constituições 
Natureza, Bem-Viver e Desenvolvimento com Equidade [...]

econômicas, dentro de um discurso de recurso econômico, estratégico para o desenvolvimento nacional, a ser administrado pelo Estado.

Primeiramente, na Constituição equatoriana, um dos objetivos do regime de desenvolvimento está na recuperação e conservação da natureza e manutenção de um meio ambiente sadio e sustentável que garanta aos seres humanos os benefícios dos recursos do subsolo e do patrimônio natural ${ }^{45}$. Além disso, estabelece o monopólio do Estado para a gestão, mediante a criação de empresas públicas ou a delegação a empresas mistas, dos setores estratégicos, entre os quais os recursos naturais não renováveis, submetidos à cobrança de royalties e outras exações pelo uso, a biodiversidade e o patrimônio genético, bem como os recursos hídricos ${ }^{46}$.

Ademais, coloca a água como patrimônio nacional estratégico de uso público, de domínio do Estado e submetida à gestão pública ou comunitária, proibida sua privatização ${ }^{47}$. Estipula que o patrimônio natural do país compreende as formações físicas, biológicas e geológicas que tenham valor ambiental, científico, cultural ou paisagístico, mas prevê o manejo sustentável dos recursos naturais ${ }^{48}$. Mais especificamente, após enumerar os recursos naturais renováveis e não renováveis como de propriedade do Estado, permite sua exploração, com participação do Estado nos benefícios, mediante mecanismos de produção, consumo e uso que permita a recuperação dos ciclos naturais 49 .

Na Bolívia, a Constituição de 2009 prevê como aspecto da economia plural a industrialização dos recursos naturais, que são de propriedade do povo boliviano e administrados pelo Estado ${ }^{50}$. O desenvolvimento produtivo industrializador dos recursos naturais é apontado como propósito da organização econômica do país para eliminar a pobreza e a exclusão social e econômica ${ }^{51}$. Mas tal industrialização deverá ocorrer segundo o respeito e a proteção do meio ambiente e dos direitos das nações e povos autóctones ${ }^{52}$.

Num segundo momento, estabelece que o patrimônio natural é de interesse público e de caráter estratégico para o desenvolvimento sustentável do país, assim como os recursos naturais - os minerais, os hidrocarbonetos, a água, o solo e o subsolo, os bosques, a biodiversidade e o espectro eletromagnético e todos os elementos e forças físicas suscetíveis de aproveitamento ${ }^{53}$. Os recursos hídricos recebem um tratamento especial $^{54}$. No bojo da administração dos recursos naturais pelo Estado, este assumirá o controle através de entidades públicas, cooperativas ou comunitárias, podendo haver empresas mistas com capital privado, deverá promover a pesquisa para $\mathrm{o}$ 
aproveitamento dos recursos naturais e priorizará a industrialização e comercialização dos recursos naturais ${ }^{55}$.

\subsection{Vedação ao monopólio e oligopólio econômicos}

As constituições que integram o Novo Constitucionalismo LatinoAmericano também se identificam quando estabelecem vedações ao monopólio, ao oligopólio e à concentração de riquezas. A Constituição brasileira de 1988, particularmente, limita-se no art. $173, \S 4^{\circ}$, a estabelecer uma aversão ao abuso do poder econômico voltado para três finalidades — dominação dos mercados, eliminação da concorrência e aumento arbitrário dos lucros - exigindo a repressão pela via legal, sem vedar o monopólio (BRASIL, 1988).

A Constituição equatoriana estabelece uma regra geral, determinando ao Estado o estabelecimento de mecanismos de sanção contra o monopólio e oligopólio privados, ou o abuso de posição dominante no mercado e outras práticas de competição desleal, bem como regra específica que inclui na política de soberania alimentar a responsabilidade do Estado de impedir práticas monopolísticas com produtos alimentícios. ${ }^{56}$ Da mesma forma, proíbe o latifúndio e a concentração de terra, bem como a retenção ou privatização da água, e de outros fatores e recursos produtivos ${ }^{57}$.

Mais especificamente, essa Constituição estabelece uma regulação econômica estatal bastante incisiva, visando a punir a usura, a exploração, a acumulação de bens essenciais, a atividade especulativa e quaisquer outros prejuízos a direitos econômicos. Para tanto, cumpre ao Estado equatoriano estabelecer uma política de controle e repressão às práticas anticoncorrenciais, em especial o monopólio e oligopólio privados, o abuso de posição econômica dominante no mercado e as práticas de competição desleal ${ }^{58}$.

Na Bolívia, sua Constituição introduz uma cláusula geral de proteção da soberania econômica, vedando a acumulação privada do poder econômico em níveis que possam pô-la em perigo ${ }^{59}$. Mais especificamente, traz claramente a proibição ao monopólio e oligopólio privados, bem como qualquer forma de associação ou acordo que pretenda o controle e a exclusividade da produção e comercialização de bens e serviços ${ }^{60}$. 
Natureza, Bem-Viver e Desenvolvimento com Equidade [...]

\title{
4 A AFIRMAÇÃO DO MODELO DESENVOLVIMENTISTA
}

Após um exame das Constituições Econômicas dos países do chamado Novo Constitucionalismo Latino-Americano, pode-se inferir, a partir de alguns dos aspectos suscitados, que esses documentos permanecem inseridos dentro de um modelo que se pode dizer desenvolvimentista. Busca, ao instituir o pluralismo jurídico econômico, conciliar o desenvolvimentismo com os valores ancestrais dos povos originários campesinos e das nações e povos indígenas traduzidos na ideia do Bemviver, de modo a que este aponte os equívocos de um modelo econômico eurocêntrico ou, se poderia dizer, setentrional. Nesse sentido:

\begin{abstract}
A positivação do Sumak Kawsay cumpre dois objetivos: [...]; no plano econômico, aponta os equívocos do desenvolvimentismo, a partir da realidade periférica. $\mathrm{O}$ Bem-Viver, assim tem uma dupla função: faz uma crítica ao modelo econômico vigente, ao mesmo tempo que propõe alternativas de reconstrução política, social e cultural da sociedade. (BRANDÃO, 2015, p. 150)
\end{abstract}

No entanto, ao apontar os equívocos e criticar o modelo econômico então vigente, essas constituições não destroem as instituições já existentes, mas busca adaptá-las para um novo conjunto de valores. Portanto, discorda-se das leituras constitucionais, aparentemente parciais, que sugerem que as constituições do Novo Constitucionalismo Latino-Americano excluem radicalmente o modelo desenvolvimentista, no sentido de que propõem o desfazimento das instituições existentes e a refundação de um novo modelo de sociedade e de vida econômica (BRANDÃO, 2015, p. 152). Aliás, o próprio texto das constituições econômicas está repleto de menções ao desenvolvimento, como passo necessário para a melhoria das condições de vida.

No entanto, vê-se que o desenvolvimento proposto por essas constituições desvia muito fortemente do clássico desenvolvimento meramente econômico, voltado apenas para o crescimento econômico. Ademais, embora já se tenha a consideração de que a noção de desenvolvimento deve vir necessariamente com desenvolvimento social e ambiental, tais constituições estabelecem um marco fundamental no sentido de colocar o desenvolvimento socioambiental à frente da lógica própria do desenvolvimento econômico. Confira-se o entendimento de Gudynas (2012, p. 50), para quem a adoção do Bem-viver suplanta versões clássicas de desenvolvimento como crescimento econômico, progresso linear e antropocentrismo, para sustentar o bem-estar das pessoas 
em um sentido mais amplo e o reconhecimento de valores intrínsecos no meio ambiente.

Um problema que merece ser enfrentado diz respeito à lógica de solução do conflito oriundo da pluralidade de modelos econômicos. Assemelhando-se ao debate em torno do pluralismo jurídico, de modo geral, entende-se que a competição de múltiplos modelos econômicos — entendidos como subsistemas sociais —, reconhecidos constitucionalmente, deve ser estabelecida de maneira sustentável, em que se há de respeitar a adequação dos vários ambientes sociais ao sistema econômico a que sejam vocacionados.

Assim, não se pode entender diferente aplicar a forma comunitária para a vida econômica das nações e povos indígenas, da mesma forma que não se pode pretender implantar o Bem-viver, em suas últimas consequências, nas cidades urbanizadas. Isso não implica que tais modelos não possam conviver e, mais do que isso, conversar entre si. Mas no momento em que é estabelecido o espaço de comunicação e haja a troca econômica entre os modelos, deve-se buscar respeitar a lógica de funcionamento interno de cada um desses sistemas. Nesse sentido, o comércio de utensílios produzidos pelas comunidades indígenas para os centros urbanos deve respeitar a lógica de mercado, enquanto a distribuição da riqueza gerada por essa troca econômica, para as comunidades indígenas, deve ser realizada segundo a lógica do Bem-viver.

Tal como foi ponderado em relação ao Direito Ambiental, a inserção do Bem-viver num modelo jurídico-econômico plural também vai dar suporte, dentro da plasticidade do Direito Econômico, a continuidade de um modelo desenvolvimentista, mas renovado pelos valores fundantes. Corroborando na construção desse novo modelo de desenvolvimento, está a preocupação em torno da soberania econômica. Em especial, destaca-se significativamente a soberania alimentar. No quadro dessas constituições, a soberania alimentar coloca-se como uma das prioridades econômicas, que deverá ser implementada de maneira sustentável, valorizando os processos de produção locais, realizados por sistemas cooperativos, artesanais ou comunitários e que promovam a proteção do meio ambiente. Assim, promovem a priorização do consumo social e ambientalmente responsável de alimentos orgânicos oriundos de produção local ou regional, preferencialmente típicos da região.

Essas considerações relativas à soberania alimentar podem ser extrapoladas para os processos produtivos econômicos de um modo geral (energia, vestuário etc.). 
Natureza, Bem-Viver e Desenvolvimento com Equidade [...]

Essas constituições estabelecem um recado muito claro para seus povos e a seus hermanos continentais, quanto à possibilidade de uma segunda via dentro do modelo desenvolvimentista.

\section{CONCLUSÕES}

Em arremate, pode-se concluir que as Constituições do Equador e da Bolívia, embora possuam constituições econômicas na esteira de outras Cartas sulamericanas inseridas em fases iniciais do Novo Constitucionalismo Latino-Americano, estabelecem de fato aspectos inovadores, que reforçam as teses de que essas constituições tragam efetivamente um "novo" constitucionalismo, colocando-as em um patamar diferenciado. São as seguintes características observadas no estudo:

a) pluralismo jurídico-econômico: as constituições reconhecem modelos de produção econômica plurais, reclamando uma mudança de compreensão normativa quanto à definição de uma política econômica por um Estado, sem prejuízo de colocar um desafio para os formuladores de políticas públicas;

b) democracia econômica: nessas constituições ela não só é mencionada como promove um giro democrático radical, conferindo aos diversos centros de poder democrático, em especial os centros locais, a prerrogativa de deliberar quanto à escolha do modelo econômico a ser adotado, e de que forma se dará a integração entre o modelo eleito com os demais;

c) soberania econômica: ela não somente é citada como tais constituições desenvolvem-na através da meta de autossuficiência produtiva em geral e do estabelecimento de prioridades em torno das questões alimentar e energética;

d) distribuição socioambiental dos resultados econômicos: não se limitando a enunciar os princípios, as constituições estabelecem regramentos mais específicos de como a tensão entre a propriedade privada e a livre iniciativa, de um lado, e a distribuição socioambiental dos resultados econômicos, de outro, deve proceder;

e) desenvolvimento do mercado interno: as constituições se valem de três fórmulas para promovê-la, uma pela autossuficiência através da industrialização, outra pela promoção da micro e pequena empresas e do associativismo, e a última pela priorização das exportações de mercadorias beneficiadas em detrimento de matérias-primas; 
f) natureza como recurso econômico: conquanto as Constituições do Equador e da Bolívia estabeleçam, de maneira inovadora, os direitos da natureza ou da Pachamama, reconhecendo personalidade jurídica à natureza, dentro das constituições econômicas a natureza continua sendo tratada como recurso econômico e estratégico para o desenvolvimento nacional;

g) vedação ao monopólio e oligopólio econômicos: as constituições não se limitam a coibir o abuso do poder econômico, mas vão além para proibir o monopólio e oligopólio econômicos, a concentração de riquezas e de terras, em consonância com um modelo de distribuição social da riqueza.

Por fim, conclui-se que a despeito da promoção do Bem-viver, essas constituições continuam a afirmar o modelo desenvolvimentista. Entretanto, dadas as características acima apontadas, tem-se uma reformulação desse modelo em bases mais condizentes com os valores ancestrais consubstanciados no Bem-viver.

\section{REFERÊNCIAS}

BERCOVICI, Gilberto. Constituição econômica e desenvolvimento: uma leitura a partir da Constituição de 1988. São Paulo: Malheiros, 2005.

BOLIVIA. Constituição (2009). Constitución Política del Estado: Estadoq Kuraq Kamachiynin: traducida al Quechua. La Paz: Konrad Adenauer; Ministerio de la Presidencia, 2012. Disponível em: <http://www.kas.de/bolivien/es/publications/33453/>. Acesso em: $1^{\circ} \mathrm{dez} .2015$.

BRANDÃO, Pedro. O novo constitucionalismo pluralista latino-americano. Rio de Janeiro: Lumen Juris, 2015.

BRASIL. Constituição (1988). Constituição da República Federativa do Brasil. Brasília, DF: Assembleia Nacional Constituinte, 1988. Disponível em: <http:// www.planalto.gov.br/ccivil_03/constituicao/constituicao.htm>. Acesso em: $1^{\mathrm{o}} \mathrm{dez}$. 2015.

DERANI, Cristiane. Direito ambiental econômico. 3. ed. São Paulo: Saraiva, 2008.

ECUADOR. Constituição (2008). Constitución de la República del Ecuador. Quito: Asamblea Constituyente, 2008. Disponível em: <http://www.asambleanacional.gov.ec/ documentos/constitucion_de_bolsillo.pdf $>$. Acesso em: $1^{\circ} \mathrm{dez} .2015$.

FIGUEIREDO, Leonardo Vizeu. Lições de direito econômico. 7. ed. Rio de Janeiro: Forense, 2014. Livro digital.

FREITAS, Juarez. Sustentabilidade: direito ao futuro. 2. ed. Belo Horizonte: Fórum, 2012. 
GUDYNAS, Eduardo. Debates sobre el desarrollo y sus alternativas en América Latina: una breve guía heterodoxa. In: JARRÍN, Sofía (Ed.). Más allá del desarrollo: Grupo Permanente de Trabajo sobre Alternativas al Desarrollo. Quito: Rosa Luxemburg; Abya Yala, 2012, p. 21-54. Disponível em: <http://rosalux.org.mx/docs/Mas_alla_del_desarrollo.pdf>. Acesso em: $1^{\text {o dez. }} 2015$.

; ACOSTA, Alberto. La renovación de la crítica al desarrollo y el buen vivir como alternativa. Utopía y praxis latinoamericana: Revista Internacional de Filosofía Iberoamericana y Teoría Social, Maracaibo, Vezenuela, año 16, n. 53, p. 71-83, abr./jun. 2011.

MORAES, Germana de Oliveira. O constitucionalismo ecocêntrico nos Andes: os direitos de Pachamama, o bem viver o direito à água. In: ; GARCIA, Marcos Leite; UNNEBERG, Flávia Soares (Org.). Para além das fronteiras: o tratamento jurídico das águas na Unasul: parte 1. Itajaí: Univali, 2012, p. 9-31. (Coleção Osvaldo Ferreira de Melo, 2). Disponível em: 〈http://www.univali.br/ppcj/ebook>. Acesso em: $1^{\circ} \mathrm{dez} .2015$.

PRADA ALCOREZA, Raúl. Análisis de la nueva constitución política del estado. In: VARGAS, Idón Moisés Chivi (Coord.). Bolivia: nueva constitución política del Estado; conceptos elementares para su desarrollo normativo. La Paz: Vicepresidencial del Estado Plurinacional, 2010, p. 181-193. Disponível em: <http://www.vicepresidencia.gob.bo/IMG/pdf/ncpe_cepd.pdf >. Acesso em: $1^{\mathrm{o}} \mathrm{dez}$. 2015.

TÁRREGA, Maria Cristina Vidotte Blanco; GONÇALVES, Daniel Diniz. Estados plurinacionais como luta insurgente emancipadora. Revista da Faculdade de Direito da UFG, v. 40, n. 1, p. 74-94, jan./jun. 2016. Disponível em: <https://revistas.ufg.emnuvens.com.br/revfd/article/view/39314/20481>. Acesso em: 12 jun. 2016.

VICIANO PASTOR, Roberto; MARTÍNEZ DALMAU, Rubén. El nuevo constitucionalismo latinoamericano: fundamentos para una construcción doctrinal. Revista General de Derecho Público Comparado, n. 9, p. 1-24, 2011.

WOLKMER, Antonio Carlos. Pluralismo e crítica do constitucionalismo na América Latina. In: SIMPÓSIO NACIONAL DE DIREITO CONSTITUCIONAL, 9., 2010, Curitiba. Anais... Curitiba: ABDConst, 2011, p. 143-155. Disponível em: <http://www.abdconst.com.br/revista3/antonioWolkmer.pdf>. Acesso em: $1^{\circ}$ dez. 2015.

; FAGUNDES, Lucas Machado. Tendências contemporâneas do constitucionalismo latino-americano: Estado plurinacional e pluralismo jurídico. Pensar, Fortaleza, v. 16, n. 2, p. 371-408, jul./dez. 2011. Disponível em: <http://ojs.unifor.br/index.php/rpen/article/viewFile/2158/1759>. Acesso em: $1^{\circ} \mathrm{dez}$. 2015.

ZAFFARONI, Eugenio Raúl. La naturaleza como persona: Pachamama y Gaia. In: VARGAS, Idón Moisés Chivi (Coord.). Bolivia: nueva constitución política del Estado; conceptos elementares para su desarrollo normativo. La Paz: Vicepresidencial del Estado Plurinacional, 2010, p. 109-132. Disponível em: 
<http://www.vicepresidencia.gob.bo/IMG/pdf/ncpe_cepd.pdf $>$. Acesso em: $1^{\circ} \mathrm{dez}$. 2015.

\footnotetext{
${ }^{1}$ Art. 275.- El régimen de desarrollo es el conjunto organizado, sostenible y dinámico de los sistemas económicos, políticos, socio-culturales y ambientales, que garantizan la realización del buen vivir, del sumak kawsay. (ECUADOR, 2008, p. 135)

${ }^{2}$ Art. 280.- El Plan Nacional de Desarrollo es el instrumento al que se sujetarán las políticas, programas y proyectos públicos; la programación y ejecución del presupuesto del Estado; y la inversión y la asignación de los recursos públicos; y coordinar las competencias exclusivas entre el Estado central y los gobiernos autónomos descentralizados. Su observancia será de carácter obligatorio para el sector público e indicativo para los demás sectores. (ECUADOR, 2008, p. 137)
}

${ }^{3}$ Art. 283.- [...].

El sistema económico se integrará por las formas de organización económica pública, privada, mixta, popular y solidaria, y las demás que la Constitución determine. La economía popular y solidaria se regulará de acuerdo con la ley e incluirá a los sectores cooperativistas, asociativos y comunitarios.

Art. 319.- Se reconocen diversas formas de organización de la producción en la economía, entre otras las comunitarias, cooperativas, empresariales públicas o privadas, asociativas, familiares, domésticas, autónomas y mixtas. (ECUADOR, 2008, p. 140 e 151)

${ }^{4}$ Artículo 306. I. El modelo económico boliviano es plural y está orientado a mejorar la calidad de vida y el vivir bien de todas las bolivianas y los bolivianos. II. La economía plural está constituida por las formas de organización económica comunitaria, estatal, privada y social cooperativa. III. La economía plural articula las diferentes formas de organización económica sobre los principios de complementariedad, reciprocidad, solidaridad, redistribución, igualdad, seguridad jurídica, sustentabilidad, equilibrio, justicia y transparencia. La economía social y comunitaria complementará el interés individual con el vivir bien colectivo. IV. Las formas de organización económica reconocidas en esta Constitución podrán constituir empresas mixtas. (BOLIVIA, 2009, p. 91)

${ }^{5}$ Artículo 308. I. El Estado reconoce, respeta y protege la iniciativa privada, para que contribuya al desarrollo económico, social y fortalezca la independencia económica del país. II. Se garantiza la libertad de empresa y el pleno ejercicio de las actividades empresariales, que serán reguladas por la ley.

Artículo 311. II. La economía plural comprende los siguientes aspectos: [...] 2. Los recursos naturales son de propiedad del pueblo boliviano y serán administrados por el Estado. Se respetará y garantizará la propiedad individual y colectiva sobre la tierra. [...] 3. La industrialización de los recursos naturales para superar la dependencia de la exportación de materias primas y lograr una economía de base productiva, en el marco del desarrollo sostenible, en armonía con la naturaleza. [...] 5. El respeto a la iniciativa empresarial y la seguridad jurídica. (BOLIVIA, 2012, p. 91-92)

${ }^{6}$ Artículo 309. La forma de organización económica estatal comprende a las empresas y otras entidades económicas de propiedad estatal, que cumplirán los siguientes objetivos: 1. Administrar a nombre del pueblo boliviano los derechos propietarios de los recursos naturales y ejercer el control estratégico de las cadenas productivas y los procesos de industrialización de dichos recursos. 2. Administrar los servicios básicos de agua potable y alcantarillado directamente o por medio de empresas públicas, comunitarias, cooperativas o mixtas. (BOLIVIA, 2012, p. 92)

7 Artículo 307. El Estado reconocerá, respetará, protegerá y promoverá la organización económica comunitaria. Esta forma de organización económica comunitaria comprende los sistemas de producción y reproducción de la vida social, fundados en los principios y visión propios de las naciones y pueblos indígena originario y campesinos. (BOLIVIA, 2012, p. 91)

${ }^{8}$ Artículo 310. El Estado reconoce y protege las cooperativas como formas de trabajo solidario y de cooperación, sin fines de lucro. Se promoverá principalmente la organización de cooperativas en actividades de producción. (BOLIVIA, 2012, p. 92)

${ }^{9}$ Artículo 309. La forma de organización económica estatal comprende a las empresas y otras entidades económicas de propiedad estatal, que cumplirán los siguientes objetivos: [...] 4. Promover la democracia económica y el logro de la soberanía alimentaria de la población. (BOLIVIA, 2012, p. 92)

${ }^{10}$ Art. 276.- El régimen de desarrollo tendrá los siguientes objetivos: [...] 4. Recuperar y conservar la naturaleza y mantener un ambiente sano y sustentable que garantice a las personas y colectividades el acceso equitativo, permanente y de calidad al agua, aire y suelo, y a los beneficios de los recursos del subsuelo y del patrimonio natural.

Art. 282.- El Estado normará el uso y acceso a la tierra que deberá cumplir la función social y ambiental. Un fondo nacional de tierra, establecido por ley, regulará el acceso equitativo de campesinos y campesinas a la tierra. 
Art. 334.- El Estado promoverá el acceso equitativo a los factores de producción, para lo cual le corresponderá: (ECUADOR, 2008, p. 135, 139 e 156)

${ }^{11}$ Artículo 313. Para eliminar la pobreza y la exclusión social y económica, para el logro del vivir bien en sus múltiples dimensiones, la organización económica boliviana establece los siguientes propósitos: [...] 3. La reducción de las desigualdades de acceso a los recursos productivos.

Artículo 353. El pueblo boliviano tendrá acceso equitativo a los beneficios provenientes del aprovechamiento de todos los recursos naturales. Se asignará una participación prioritaria a los territorios donde se encuentren estos recursos, y a las naciones y pueblos indígena originario campesinos. (BOLIVIA, 2012, p. 93 e 103)

12 Art. 284.- La política económica tendrá los siguientes objetivos: [...] 3. Asegurar la soberanía alimentaria y energética.

Art. 334.- El Estado promoverá el acceso equitativo a los factores de producción, para lo cual le corresponderá: [...] 4. Desarrollar políticas de fomento a la producción nacional en todos los sectores, en especial para garantizar la soberanía alimentaria y la soberanía energética, generar empleo y valor agregado. (ECUADOR, 2008, p. 140 e 156-157)

${ }^{13}$ Art. 15.- El Estado promoverá, en el sector público y privado, el uso de tecnologías ambientalmente limpias y de energías alternativas no contaminantes y de bajo impacto. La soberanía energética no se alcanzará en detrimento de la soberanía alimentaria, ni afectará el derecho al agua.

Art. 281.- La soberanía alimentaria constituye un objetivo estratégico y una obligación del Estado para garantizar que las personas, comunidades, pueblos y nacionalidades alcancen la autosuficiencia de alimentos sanos y culturalmente apropiado de forma permanente. (ECUADOR, 2008, p. 24 e 138)

${ }^{14}$ Artículo 318. I. El Estado determinará una política productiva industrial y comercial que garantice una oferta de bienes y servicios suficiente para cubrir de forma adecuada las necesidades básicas internas, y para fortalecer la capacidad exportadora. (BOLIVIA, 2012, p. 94)

15 Artículo 309. La forma de organización económica estatal comprende a las empresas y otras entidades económicas de propiedad estatal, que cumplirán los siguientes objetivos: [...] 4. Promover la democracia económica y el logro de la soberanía alimentaria de la población.

Artículo 405. El desarrollo rural integral sustentable es parte fundamental de las políticas económicas del Estado, que priorizará sus acciones para el fomento de todos los emprendimientos económicos comunitarios y del conjunto de los actores rurales, con énfasis en la seguridad y en la soberanía alimentaria, a través de: (BOLIVIA, 2012, p. 92 e 114)

16 Artículo 360. El Estado definirá la política de hidrocarburos, promoverá su desarrollo integral, sustentable y equitativo, y garantizará la soberanía energética. (BOLIVIA, 2012, p. 104)

${ }^{17}$ Artículo 320. [...] V. Las políticas públicas promocionarán el consumo interno de productos hechos en Bolivia. (BOLIVIA, 2012, p. 95)

18 Art. 276.- El régimen de desarrollo tendrá los siguientes objetivos: [...] 2. Construir un sistema económico, justo, democrático, productivo, solidario y sostenible basado en la distribución igualitaria de los beneficios del desarrollo, de los medios de producción y en la generación de trabajo digno y estable. [...] 4. Recuperar y conservar la naturaleza y mantener un ambiente sano y sustentable que garantice a las personas y colectividades el acceso equitativo, permanente y de calidad al agua, aire y suelo, y a los beneficios de los recursos del subsuelo y del patrimonio natural. (ECUADOR, 2008, p. 135)

19 Art. 282.- El Estado normará el uso y acceso a la tierra que deberá cumplir la función social y ambiental. Un fondo nacional de tierra, establecido por ley, regulará el acceso equitativo de campesinos y campesinas a la tierra. (ECUADOR, 2008, p. 139)

20 Art. 306.- El Estado promoverá las exportaciones ambientalmente responsables, con preferencia de aquellas que generen mayor empleo y valor agregado, y en particular las exportaciones de los pequeños y medianos productores y del sector artesanal. (ECUADOR, 2008, p. 146)

${ }^{21}$ Art. 281.- La soberanía alimentaria constituye un objetivo estratégico y una obligación del Estado para garantizar que las personas, comunidades, pueblos y nacionalidades alcancen la autosuficiencia de alimentos sanos y culturalmente apropiado de forma permanente. Para ello, será responsabilidad del Estado: [...] 11. Generar sistemas justos y solidarios de distribución y comercialización de alimentos. Impedir prácticas monopólicas y cualquier tipo de especulación con productos alimenticios. (ECUADOR, 2008, p. 138)

22 Art. 284.- La política económica tendrá los siguientes objetivos: [...] 1. Asegurar una adecuada distribución del ingreso y de la riqueza nacional. [...] 7. Mantener la estabilidad económica, entendida como el máximo nivel de producción y empleo sostenibles en el tiempo. (ECUADOR, 2008, p. 140)

23 Art. 334.- El Estado promoverá el acceso equitativo a los factores de producción, para lo cual le corresponderá: 1. Evitar la concentración o acaparamiento de factores y recursos productivos, promover su redistribución y eliminar privilegios o desigualdades en el acceso a ellos. 2. Desarrollar políticas 
específicas para erradicar la desigualdad y discriminación hacia las mujeres productoras, en el acceso a los factores de producción. 3. Impulsar y apoyar el desarrollo y la difusión de conocimientos y tecnologías orientados a los procesos de producción. [...] 5. Promover los servicios financieros públicos y la democratización del crédito. (ECUADOR, 2008, p. 156-157)

24 Art. 14.- Se reconoce el derecho de la población a vivir en un ambiente sano y ecológicamente equilibrado, que garantice la sostenibilidad y el buen vivir, sumak kawsay. Se declara de interés público la preservación del ambiente, la conservación de los ecosistemas, la biodiversidad y la integridad del patrimonio genético del país, la prevención del daño ambiental y la recuperación de los espacios naturales degradados. (ECUADOR, 2008, p. 14)

25 Art. 284.- La política económica tendrá los siguientes objetivos: [...] 4. Promocionar la incorporación del valor agregado con máxima eficiencia, dentro de los límites biofísicos de la naturaleza y el respeto a la vida y a las culturas. (ECUADOR, 2008, p. 140)

${ }^{26}$ Art. 15.- El Estado promoverá, en el sector público y privado, el uso de tecnologías ambientalmente limpias y de energías alternativas no contaminantes y de bajo impacto. La soberanía energética no se alcanzará en detrimento de la soberanía alimentaria, ni afectará el derecho al agua. (ECUADOR, 2008, p. 14)

27 Art. 57.- Se reconoce y garantizará a las comunas, comunidades, pueblos y nacionalidades indígenas, de conformidad con la Constitución y con los pactos, convenios, declaraciones y demás instrumentos internacionales de derechos humanos, los siguientes derechos colectivos: [...] 8. Conservar y promover sus prácticas de manejo de la biodiversidad y de su entorno natural. El Estado establecerá y ejecutará programas, con la participación de la comunidad, para asegurar la conservación y utilización sustentable de la biodiversidad. (ECUADOR, 2008, p. 41-42)

28 Art. 313.- El Estado se reserva el derecho de administrar, regular, controlar y gestionar los sectores estratégicos, de conformidad con los principios de sostenibilidad ambiental, precaución, prevención y eficiencia. Se consideran sectores estratégicos la energía en todas sus formas, las telecomunicaciones, los recursos naturales no renovables, el transporte y la refinación de hidrocarburos, la biodiversidad y el patrimonio genético, el espectro radioeléctrico, el agua, y los demás que determine la ley. (ECUADOR, 2008, p. 149)

${ }^{29}$ Art. 315.- El Estado constituirá empresas públicas para la gestión de sectores estratégicos, la prestación de servicios públicos, el aprovechamiento sustentable de recursos naturales o de bienes públicos y el desarrollo de otras actividades económicas. (ECUADOR, 2008, p. 149)

30 Art. 317.- Los recursos naturales no renovables pertenecen al patrimonio inalienable e imprescriptible del Estado. En su gestión, el Estado priorizará la responsabilidad intergeneracional, la conservación de la naturaleza, el cobro de regalías u otras contribuciones no tributarias y de participaciones empresariales; y minimizará los impactos negativos de carácter ambiental, cultural, social y económico. (ECUADOR, 2008, p. 150)

${ }^{31}$ Artículo 312. [...] II. Todas las formas de organización económica tienen la obligación de generar trabajo digno, y contribuir a la reducción de las desigualdades y a la erradicación de la pobreza.

Artículo 313. Para eliminar la pobreza y la exclusión social y económica, para el logro del vivir bien en sus múltiples dimensiones, la organización económica boliviana establece los siguientes propósitos: 1. Generación del producto social en el marco del respeto de los derechos individuales, así como de los derechos de los pueblos y las naciones. 2. La producción, distribución y redistribución justa de la riqueza y de los excedentes económicos. 3. La reducción de las desigualdades de acceso a los recursos productivos. (BOLIVIA, 2012, p. 92-93)

${ }^{32}$ Artículo 312. [...] III. Todas las formas de organización económica tienen la obligación de proteger el medio ambiente.

Artículo 342. [...] Es deber del Estado y de la población conservar, proteger y aprovechar de manera sustentable los recursos naturales y la biodiversidad, así como mantener el equilibrio del medio ambiente. (BOLIVIA, 2012, p. 92-93 e 101)

${ }^{33}$ Artículo 316. La función del Estado en la economía consiste en: [...] 5. Promover la integración de las diferentes formas económicas de producción, con el objeto de lograr el desarrollo económico y social. 6. Promover prioritariamente la industrialización de los recursos naturales renovables y no renovables, en el marco del respeto y protección del medio ambiente, para garantizar la generación de empleo y de insumos económicos y sociales para la población. 7. Promover políticas de distribución equitativa de la riqueza y de los recursos económicos del país, con el objeto de evitar la desigualdad, la exclusión social y económica, y erradicar la pobreza en sus múltiples dimensiones. (BOLIVIA, 2012, p. 93-94)

${ }^{34}$ Artículo 346. El patrimonio natural es de interés público y de carácter estratégico para el desarrollo sustentable del país. Su conservación y aprovechamiento para beneficio de la población será 
responsabilidad y atribución exclusiva del Estado, y no comprometerá la soberanía sobre los recursos naturales. La ley establecerá los principios y disposiciones para su gestión.

Artículo 353. El pueblo boliviano tendrá acceso equitativo a los beneficios provenientes del aprovechamiento de todos los recursos naturales. Se asignará una participación prioritaria a los territorios donde se encuentren estos recursos, y a las naciones y pueblos indígena originario campesinos.

Artículo 380. I. Los recursos naturales renovables se aprovecharán de manera sustentable, respetando las características y el valor natural de cada ecosistema. (BOLIVIA, 2012, p. 101, 103 e 109)

${ }^{35}$ Artículo 397. I. El trabajo es la fuente fundamental para la adquisición y conservación de la propiedad agraria. Las propiedades deberán cumplir con la función social o con la función económica social para salvaguardar su derecho, de acuerdo a la naturaleza de la propiedad. II. La función social se entenderá como el aprovechamiento sustentable de la tierra por parte de pueblos y comunidades indígena originario campesinos, así como el que se realiza en pequeñas propiedades, y constituye la fuente de subsistencia y de bienestar y desarrollo sociocultural de sus titulares. En el cumplimiento de la función social se reconocen las normas propias de las comunidades. III. La función económica social debe entenderse como el empleo sustentable de la tierra en el desarrollo de actividades productivas, conforme a su capacidad de uso mayor, en beneficio de la sociedad, del interés colectivo y de su propietario. La propiedad empresarial está sujeta a revisión de acuerdo con la ley, para verificar el cumplimiento de la función económica y social. (BOLIVIA, 2012, p. 113)

${ }^{36}$ Artículo 255. [...]. II. La negociación, suscripción y ratificación de tratados internacionales se regirá por los principios de: [...] 11. Protección y preferencias para la producción boliviana, y fomento a las exportaciones con valor agregado. (BOLIVIA, 2012, p. 73)

37 Artículo 311. [...] II. La economía plural comprende los siguientes aspectos: [...] 3. La industrialización de los recursos naturales para superar la dependencia de la exportación de materias primas y lograr una economía de base productiva, en el marco del desarrollo sostenible, en armonía con la naturaleza. (BOLIVIA, 2012, p. 92)

${ }^{38}$ Artículo 313. Para eliminar la pobreza y la exclusión social y económica, para el logro del vivir bien en sus múltiples dimensiones, la organización económica boliviana establece los siguientes propósitos: [...] 5. El desarrollo productivo industrializador de los recursos naturales. (BOLIVIA, 2012, p. 93)

${ }^{39}$ Artículo 316. La función del Estado en la economía consiste en: [...] 6. Promover prioritariamente la industrialización de los recursos naturales renovables y no renovables, en el marco del respeto y protección del medio ambiente, para garantizar la generación de empleo, y de insumos económicos y sociales para la población. (BOLIVIA, 2012, p. 93-94)

${ }^{40}$ Artículo 318. I. El Estado determinará una política productiva industrial y comercial que garantice una oferta de bienes y servicios suficiente para cubrir de forma adecuada las necesidades básicas internas, y para fortalecer la capacidad exportadora. (BOLIVIA, 2012, p. 94)

${ }^{41}$ Artículo 318. [...] II. El Estado reconoce y priorizará el apoyo a la organización de estructuras asociativas de pequeños productores, urbanos y rurales. [...] IV. El Estado promoverá y apoyará la exportación de bienes con valor agregado y los servicios. (BOLIVIA, 2012, p. 94)

42 Artículo 319. I. La industrialización de los recursos naturales será prioridad en las políticas económicas, en el marco del respeto y protección del medio ambiente y de los derechos de las naciones y pueblos indígena originario campesinos y sus territorios. La articulación de la explotación de los recursos naturales con el aparato productivo interno será prioritaria en las políticas económicas del Estado. (BOLIVIA, 2012, p. 95)

${ }^{43}$ Art. 71.- La naturaleza o Pacha Mama, donde se reproduce y realiza la vida, tiene derecho a que se respete integralmente su existencia y el mantenimiento y regeneración de sus ciclos vitales, estructura, funciones y procesos evolutivos. (ECUADOR, 2008, p. 52)

${ }^{44}$ Artículo 108. Son deberes de las bolivianas y los bolivianos: [...] 16. Proteger y defender um medio ambiente adecuado para el desarrollo de los seres vivos. (BOLIVIA, 2012, p. 34)

${ }^{45}$ Art. 276.- El régimen de desarrollo tendrá los siguientes objetivos: [...] 4. Recuperar y conservar la naturaleza y mantener un ambiente sano y sustentable que garantice a las personas y colectividades el acceso equitativo, permanente y de calidad al agua, aire y suelo, y a los beneficios de los recursos del subsuelo y del patrimonio natural. (ECUADOR, 2008, p. 135)

${ }^{46}$ Art. 313.- El Estado se reserva el derecho de administrar, regular, controlar y gestionar los sectores estratégicos, de conformidad con los principios de sostenibilidad ambiental, precaución, prevención y eficiencia. Se consideran sectores estratégicos [...] los recursos naturales no renovables, [...] la biodiversidad y el patrimonio genético, [...], el agua, y los demás que determine la ley.

Art. 315.- El Estado constituirá empresas públicas para la gestión de sectores estratégicos, la prestación de servicios públicos, el aprovechamiento sustentable de recursos naturales o de bienes públicos y el desarrollo de otras actividades económicas. [...] 
Art. 317.- Los recursos naturales no renovables pertenecen al patrimonio inalienable e imprescriptible del Estado. En su gestión, el Estado priorizará la responsabilidad intergeneracional, la conservación de la naturaleza, el cobro de regalías u otras contribuciones no tributarias y de participaciones empresariales; y minimizará los impactos negativos de carácter ambiental, cultural, social y económico. (ECUADOR, 2008, p. 149-150)

47 Art. 318.- El agua es patrimonio nacional estratégico de uso público, dominio inalienable e imprescriptible del Estado, y constituye un elemento vital para la naturaleza y para la existencia de los seres humanos. Se prohíbe toda forma de privatización del agua. La gestión del agua será exclusivamente pública o comunitaria. El servicio público de saneamiento, el abastecimiento de agua potable y el riego serán prestados únicamente por personas jurídicas estatales o comunitarias. (ECUADOR, 2008, p. 150)

${ }^{48}$ Art. 404.- El patrimonio natural del Ecuador único e invaluable comprende, entre otras, las formaciones físicas, biológicas y geológicas cuyo valor desde el punto de vista ambiental, científico, cultural o paisajístico exige su protección, conservación, recuperación y promoción. Su gestión se sujetará a los principios y garantías consagrados en la Constitución y se llevará a cabo de acuerdo al ordenamiento territorial y una zonificación ecológica, de acuerdo con la ley.

Art. 397.- [...] Para garantizar el derecho individual y colectivo a vivir en un ambiente sano y ecológicamente equilibrado, el Estado se compromete a: [...] 2. Establecer mecanismos efectivos de prevención y control de la contaminación ambiental, de recuperación de espacios naturales degradados y de manejo sustentable de los recursos naturales. (ECUADOR, 2008, p. 178 e 180)

49 Art. 408.- Son de propiedad inalienable, imprescriptible e inembargable del Estado los recursos naturales no renovables y, en general, los productos del subsuelo, yacimientos minerales y de hidrocarburos, substancias cuya naturaleza sea distinta de la del suelo, incluso los que se encuentren en las áreas cubiertas por las aguas del mar territorial y las zonas marítimas; así como la biodiversidad y su patrimonio genético y el espectro radioeléctrico. Estos bienes sólo podrán ser explotados en estricto cumplimiento de los principios ambientales establecidos en la Constitución. El Estado participará en los beneficios del aprovechamiento de estos recursos, en un monto que no será inferior a los de la empresa que los explota. El Estado garantizará que los mecanismos de producción, consumo y uso de los recursos naturales y la energía preserven y recuperen los ciclos naturales y permitan condiciones de vida con dignidad. (ECUADOR, 2008, p. 181)

50 Artículo 311. [...] II. La economía plural comprende los siguientes aspectos: [...] 2. Los recursos naturales son de propiedad del pueblo boliviano y serán administrados por el Estado. Se respetará y garantizará la propiedad individual y colectiva sobre la tierra. 3. La industrialización de los recursos naturales para superar la dependencia de la exportación de materias primas y lograr una economía de base productiva, en el marco del desarrollo sostenible, en armonía con la naturaleza. (BOLIVIA, 2012, p. 92) ${ }^{51}$ Artículo 313. Para eliminar la pobreza y la exclusión social y económica, para el logro del vivir bien en sus múltiples dimensiones, la organización económica boliviana establece los siguientes propósitos: [...] 5. El desarrollo productivo industrializador de los recursos naturales. (BOLIVIA, 2012, p. 93)

52 Artículo 319. I. La industrialización de los recursos naturales será prioridad en las políticas económicas, en el marco del respeto y protección del medio ambiente y de los derechos de las naciones y pueblos indígena originario campesinos y sus territorios. La articulación de la explotación de los recursos naturales con el aparato productivo interno será prioritaria en las políticas económicas del Estado. (BOLIVIA, 2012, p. 95)

${ }^{53}$ Artículo 346. El patrimonio natural es de interés público y de carácter estratégico para el desarrollo sustentable del país. Su conservación y aprovechamiento para beneficio de la población será responsabilidad y atribución exclusiva del Estado, y no comprometerá la soberanía sobre los recursos naturales. La ley establecerá los principios y disposiciones para su gestión.

Artículo 348. I. Son recursos naturales los minerales en todos sus estados, los hidrocarburos, el agua, el aire, el suelo y el subsuelo, los bosques, la biodiversidad, el espectro electromagnético y todos aquellos elementos y fuerzas físicas susceptibles de aprovechamiento. II. Los recursos naturales son de carácter estratégico y de interés público para el desarrollo del país. (BOLIVIA, 2012, p. 101-102)

54 Artículo 376. Los recursos hídricos de los ríos, lagos y lagunas que conforman las cuencas hidrográficas, por su potencialidad, por la variedad de recursos naturales que contienen y por ser parte fundamental de los ecosistemas, se consideran recursos estratégicos para el desarrollo y la soberanía boliviana. El Estado evitará acciones en las nacientes y zonas intermedias de los ríos que ocasionen daños a los ecosistemas o disminuyan los caudales, preservará el estado natural y velará por el desarrollo y bienestar de la población.

55 Artículo 351. I. El Estado, asumirá el control y la dirección sobre la exploración, explotación, industrialización, transporte y comercialización de los recursos naturales estratégicos a través de 
entidades públicas, cooperativas o comunitarias, las que podrán a su vez contratar a empresas privadas y constituir empresas mixtas.

Artículo 354. El Estado desarrollará y promoverá la investigación relativa al manejo, conservación y aprovechamiento de los recursos naturales y la biodiversidad.

Artículo 355. I. La industrialización y comercialización de los recursos naturales será prioridad del Estado. (BOLIVIA, 2012, p. 102-103)

${ }^{56}$ Art. 281.- La soberanía alimentaria constituye un objetivo estratégico y una obligación del Estado para garantizar que las personas, comunidades, pueblos y nacionalidades alcancen la autosuficiencia de alimentos sanos y culturalmente apropiado de forma permanente.

Para ello, será responsabilidad del Estado: [...] 11. Generar sistemas justos y solidarios de distribución y comercialización de alimentos. Impedir prácticas monopólicas y cualquier tipo de especulación con productos alimenticios.

Art. 335.- [...]. El Estado definirá una política de precios orientada a proteger la producción nacional, establecerá los mecanismos de sanción para evitar cualquier práctica de monopolio y oligopolio privados, o de abuso de posición de dominio en el mercado y otras prácticas de competencia desleal. (ECUADOR, 2008, p. 138 e 157)

${ }^{57}$ Art. 282.- [...]. Se prohíbe el latifundio y la concentración de la tierra, así como el acaparamiento o privatización del agua y sus fuentes.

Art. 334.- El Estado promoverá el acceso equitativo a los factores de producción, para lo cual le corresponderá: 1. Evitar la concentración o acaparamiento de factores y recursos productivos, promover su redistribución y eliminar privilegios o desigualdades en el acceso a ellos. (ECUADOR, 2008, p. 139 e 156)

${ }^{58}$ Art. 335.- El Estado regulará, controlará e intervendrá, cuando sea necesario, en los intercambios y transacciones económicas; y sancionará la explotación, usura, acaparamiento, simulación, intermediación especulativa de los bienes y servicios, así como toda forma de perjuicio a los derechos económicos y a los bienes públicos y colectivos. El Estado definirá una política de precios orientada a proteger la producción nacional, establecerá los mecanismos de sanción para evitar cualquier práctica de monopolio y oligopolio privados, o de abuso de posición de dominio en el mercado y otras prácticas de competencia desleal. (ECUADOR, 2008, p. 157)

${ }^{59}$ Artículo 312. I. Toda actividad económica debe contribuir al fortalecimiento de la soberanía económica del país. No se permitirá la acumulación privada de poder económico en grado tal que ponga en peligro la soberanía económica del Estado. (BOLIVIA, 2012, p. 92)

${ }^{60}$ Artículo 314. Se prohíbe el monopolio y el oligopolio privado, así como cualquier otra forma de asociación o acuerdo de personas naturales o jurídicas privadas, nacionales o extranjeras, que pretendan el control y la exclusividad en la producción y la comercialización de bienes y servicios. (BOLIVIA, 2012, p. 93). 
Álisson José Maia Melo

Artigo recebido em 12 de fevereiro de 2016 e aceito em 07 de junho de 2016 